\title{
Na página ímpar, os jovens de 1968: publicidade e representações sociais nas revistas Veja e Realidade
}

\author{
Cláudia da Silva Pereira
}

Resumo: O presente trabalho tem por objetivo analisar dez anúncios publicados nas revistas Veja e Realidade nos anos de 1967 e 1968, buscando compreender, a partir de um determinado contexto cultural, social e político, de que forma se constrói, na mídia, a ideia de juventude. A metodologia contou com revisão de literatura, pesquisa documental nas duas revistas e análise das representações midiáticas acerca da cultura, valores e práticas dos jovens. Como resultado, estabeleceram-se algumas possíveis categorias de tipos ideais presentes na narrativa publicitária. Percebe-se, ao longo da análise, que a mídia se apropria de valores positivos atribuídos aos jovens, ao mesmo tempo que contribui para a fixação da oposição entre jovens e adultos.

Palavras-chave: juventude; publicidade; representações sociais; revista Veja; revista Realidade

\begin{abstract}
On the odd page, the youth of 68: advertising and social representations in the magazines Veja and Realidade - This study analyzes 10 ads published in the magazines Veja and Realidade in 1967 and 1968, seeking to understand how the notion of youth is constructed by the media within a particular cultural, social and political context. The methodology consists of a literature review, a documentary research of the two magazines, and an analysis of the media representations of youth culture, values and practices. This leads to the establishment of several possible ideal-type categories that are present in the advertising narrative. Throughout the analysis, one finds that the media uses positive values attributed to youth, while contributing to cement the opposition between youth and adult.
\end{abstract}

Keywords: youth; advertising; social representations; Veja magazine; Realidade magazine

Do lado direito das revistas e jornais impressos, em geral, encontramos as notícias mais interessantes e os anúncios mais atrativos. O encontro dos olhos com a página ímpar é sensivelmente mais longo: dois, três segundos a mais bastam para a mensagem se fixar na memória. 
O objetivo deste artigo é mapear alguns significados da juventude no contexto brasileiro do final dos anos 1960. A publicidade já dedicava, naquela década, um espaço privilegiado para os jovens, sua cultura e seus símbolos, nas páginas de revistas como Veja e Realidade, que servem de principais fontes documentais para a seleção do corpus aqui apresentado: 12 peças, dentre elas, anúncios publicitários, matérias e capas de revistas.

Para discutir o conceito de juventude a partir da perspectiva da comunicação, parte-se das ideias de Morin (2009; 2011), Grossberg (1983; 2010), Caldas (2008), entre outros autores que também são acionados para sustentar a proposição do surgimento de uma cultura de consumo relacionada aos jovens.

Uma revisão de literatura acerca do conceito de juventude relacionado à cultura midiática, uma pesquisa documental que seleciona os exemplos de anúncios e capas publicados nos anos de 1967 e 1968 nas duas revistas já mencionadas, quais sejam, Veja e Realidade, e a análise das representações sociais presentes na mídia compõem, enfim, este artigo.

\section{Os jovens e a cultura de massa}

Morin debruçou-se sobre o tema "juventude" e suas relações com a cultura de massa em dois momentos principais: no primeiro, Morin (2011 [1962]) reconhece na figura do jovem ainda incipiente uma condição de "mitologia"; cerca de uma década depois, a "cultura juvenil", como o próprio autor denomina, ocupa um importante espaço social e cultural em um momento de crise (MORIN, 2009 [1975]).

Nos anos 1960, esse autor refletia sobre uma cultura de massas em construção, delineando o que seriam os valores norteadores que a sustentavam no contexto da sociedade americana, em primeiro lugar, e das sociedades ocidentais, num segundo momento - dentre os quais, a felicidade, o hedonismo, o feminino e, o qual nos interessa em especial, a juventude -, pautando uma comunicação que homogeneíza os gostos e padroniza os estilos de vida.

Morin (ibid.) demonstrou que tudo teve início com a adesão desses mesmos jovens, enquanto "classe de idade", aos movimentos feministas e antirracistas dos anos 1950, provocando imediata identificação com os anti-heróis de filmes como The Wild One (1953), com Marlon Brando, e Rebel Without a Cause (1955), com James Dean, instigando-os a imitarem seus modos e suas modas e, sobretudo, a organizarem-se em gangues pelas ruas dos Estados Unidos e Europa para, mais tarde, aportarem no Brasil.

Sobre a chegada do rock n'roll ao país, em 1955, com a gravação da música Rock Around the Clock pela cantora de boleros Nora Ney, Caldas (2008) aponta que somente um ano depois o novo ritmo se disseminou entre os jovens. De fato, foi em 1956, com o filme Balanço das Horas, que a gravação original de Bill Haley e seus Cometas levou o Brasil para o rol dos países consumidores da indústria cultural norte-americana. 
A cultura de massas se consolidou, sobretudo, no governo do presidente Juscelino Kubitschek (1956-1961), com a abertura do mercado para os importados. Chegaram aqui, entre outros produtos como a Coca-Cola, os rádios portáteis de pilha (ibid.), talvez os primeiros gadgets que permitiram uma mobilidade incorporada até hoje pelo estilo de vida dos jovens, e que se associaram a outros bens simbólicos específicos, instalando-se, especialmente, nos centros urbanos brasileiros, como demonstra Caldas, e tornando-se, paulatinamente, a referência cultural do país.

Podia-se já identificar uma "nova cultura da juventude" (ibid., p. 76) facilitada, sobretudo, por sua relação direta com o processo de urbanização daquela sociedade brasileira. E, como tal, contribuiu, paralelamente, para a sedimentação de uma cultura de massas definitiva. Até mesmo as emissoras de rádio rurais passaram a ser solicitadas a também incluírem em sua programação musical o rock n'roll. Entretanto, esses jovens eram tão conservadores quanto seus próprios pais, ou seja, sempre estiveram de acordo com o status quo, como esperam a família e o Estado. A música é que era esteticamente revolucionária (ibid.).

Por seu turno, Grossberg (1983) assume o rock n'roll a partir de sua forma cultural e afetiva e, sendo de tal modo compreendido, torna-o um de seus objetos de estudo mais centrais. Para esse autor, há uma "aliança afetiva" no rock and roll, uma espécie de conjunto concreto e material de práticas e experiências, culturais e sociais, que tem seu lugar dentro de "possibilidades históricas de desejo" - as quais compreendem, por princípio, a luta pelo poder. Nesse sentido, o rock and roll demarcaria um espaço de "alteridade, uma existência externa às demais possibilidades afetivas de alianças hegemônicas" (ibid., p. 105) - ele é, antes, um marcador social, uma "arte interna" à cultura dominante que acaba por colocar seus fãs "à parte", como outsiders (ibid., p. 109).

É, portanto, na esfera do afeto, ou melhor, de "organização dos afetos", que Grossberg localiza esse produto cultural, analisando, especificamente, o caso norte-americano do pós-guerra. Segundo ele, "o rock and roll é uma forma de rebelião cultural e nunca de revolução política" (ibid., p. 105). Embora não necessária e exclusivamente uma expressão étnica, etária ou de classe, ou própria de qualquer tipo de identidade cultural, essa aliança afetiva se estabeleceu entre crianças e adolescentes dos anos 1950, ainda segundo Grossberg, que se sentiam desamparados, isolados e solitários, diante de um mundo em brutal mudança conjuntural.

A cultura juvenil constitui uma resposta ao contexto em que as experiências dos jovens e do próprio rock and roll se davam. Os níveis de crescimento e progresso romperam com a conformidade temporal, passado-presente-futuro, o que reforçaria o caráter único daquela juventude do pós-guerra, completamente apartada, afetivamente, da cultura dominante e, de certo modo, amparada pelo rock and roll, naquele momento. Hobsbawn (1995) também corrobora o ponto de vista de Grossberg, num certo sentido, ao demonstrar que a ruptura com os costumes que vigoravam antes da Segunda Guerra Mundial acabou gerando um abismo geracional intransponível. 
O nascimento de uma cultura juvenil está, pelo menos segundo esses autores, ancorada na emergência de uma nova forma cultural que irrompe por entre o grosso, porém desgastado, tecido social do conservadorismo norte-americano: o rock and roll. Trata-se, porém, mais de um meio do que de um fim, de um caminho do que de um destino, ele é, como afirmou Grossberg, uma "organização dos afetos" de toda uma geração. Pelos meios de comunicação de massa, a sociedade de consumo incorpora os símbolos desse novo e oportuno estilo de vida, levando a reboque a juventude. Mas uma juventude que se deixa levar - seus afetos ainda não estão organizados, estão apenas em vias de...

Trata-se de uma geração, esta do pós-guerra, que é representada na mídia como transgressora, embora não o seja, ainda, tanto; embora não esteja, em outras palavras, madura o suficiente para transgredir. Ainda faltava, naquele momento, uma maior sedimentação dos propósitos juvenis para que eles pudessem se colocar à frente dessa onda e conduzi-la na direção contrária aos tradicionais costumes aos quais, afinal, opunham-se, por direito. Configurava-se, porém, um cenário social e cultural que favorecia o esgarçamento dessa brecha aberta pelos jovens dos anos 1950 - um cenário que Grossberg (2010, p. 3-6) denomina "rock formation", uma "configuração particular", segundo ele, de "música/cultura popular e jovem", vias pelas quais se insurgiriam os movimentos contraculturais.

Ainda longe dos efeitos da globalização, entremeados por oceanos e distâncias culturais, esses jovens encontraram, no consumo e na música, uma mesma plataforma de diálogo e de resistência. A publicidade, naquele momento, estabelece as representações desse contexto, aproximando a música - o rock e, depois, a bossa-nova, como veremos - da juventude, criando uma relação muito próxima entre uma e outra.

Pois foi ainda nos Estados Unidos de meados dos anos 1950 que o Uivo, de Allen Ginsberg - precedido ainda pelos hipsters, "boêmios brancos e negros vivendo nos limites da economia, saindo juntos, especialmente em clubes de jazz" (GOFFMAN; JOY, 2007, p. 256) -, inspirava e anunciava a Contracultura. Em contraposição à noção mais ampla de contracultura (com c minúsculo), a Contracultura é um movimento situado num determinado contexto social e histórico, mais especificamente na virada da década de 1960 para a de 1970, como o movimento hippie, entre outras formas de expressão antiautoritarista e libertária(ibid.).

Desenhava-se, portanto, os contornos de uma fronteira que se estabelecia entre os jovens e os outros - os adultos; uma oposição simbólica que perduraria até a contemporaneidade na mídia, em suas diversas expressões, entre aqueles que têm "vinte e cinco e menos", como destaca a capa da Time de 6 de janeiro 1967 (Figura 1), e os "outros". 

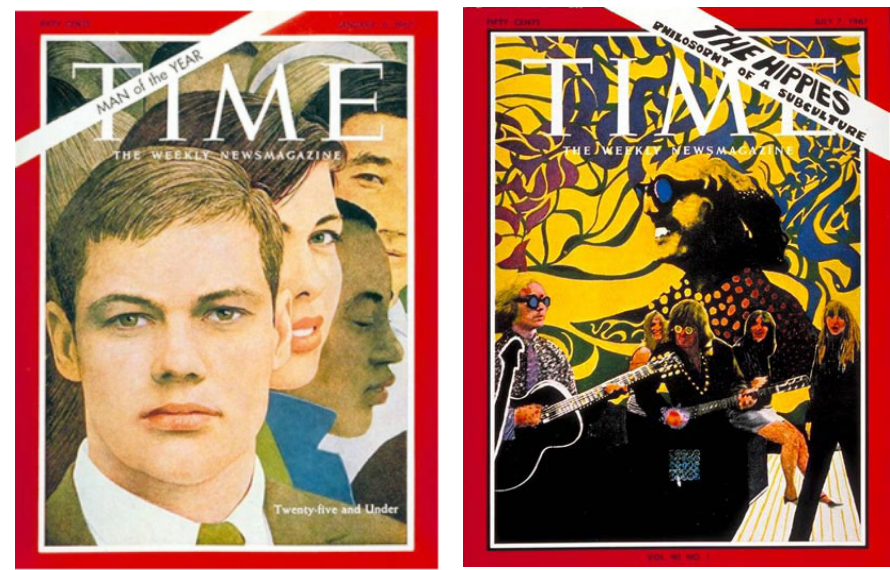

Fig. 1. Capas da Time Magazine em 1967 - à esquerda,

"Twenty-five and Under" (6 de janeiro); à direita, "The hippies" (7de julho)

Na revista Time, em sua edição de janeiro, evidencia-se a enorme preocupação com uma geração que parecia invisível ou, talvez, inofensiva. Seja pelo contingente populacional que representa, seja pela resistência aos padrões culturais de uma época, os jovens ganham destaque neste que é um dos mais influentes veículos de comunicação norte-americanos, até hoje.

For the Man of the Year 1966 is a generation: the man-and woman-of 25 and under. In the closing third of the 20th century, that generation looms larger than all the exponential promises of science or technology: it will soon be the majority in charge. (...) If the statistics imply change, the credentials of the younger generation guarantee it. Never have the young been so assertive or so articulate, so well educated or so worldly. Predictably, they are a highly independent breed, and-to adult eyes - their independence has made them highly unpredictable. This is not just a new generation, but a new kind of generation.

São numerosos e, como sugere a matéria, independentes e imprevisíveis. Ao longo das onze páginas do texto, que procura sintetizar o que seria este "novo tipo de geração", constrói-se a imagem de uma juventude que ameaça os padrões morais hegemônicos, adultos, mas que, proporcionalmente, não representa a maioria. O que se percebe é um esforço, não raro no discurso jornalístico, de deslegitimação do ativismo político dos que têm em torno de 20 anos. Ao analisar os anúncios publicitários, mais adiante, pode-se perceber que a intenção é praticamente oposta - embora os efeitos de tal comunicação não o sejam - no sentido de valorizar e instaurar esse estilo de vida geracional.

Ao mesmo tempo que se assume a centralidade da juventude como pauta jornalística, destacam-se, recorrentemente, referências à ineficiência dos protestos, que se fazem 
parecer mais alardeados do que factuais. O "fiasco" de Berkeley, como relatado abaixo, é também, para a "moderna comunicação", algo que merece o "centro do palco".

Modern communications have done much to put them on center stage. Returning from a recent rally on the Berkeley campus, one U.C. coed reported that the demonstration had been a fiasco. "Why," she lamented, "we didn't get a single TV camera!"

O hedonismo já aparece, em 1967, como marca dos jovens. Sempre no esforço de tomar essa geração dos anos 1960 como alienada, salta aos olhos a forma como o texto da Time Magazine estabelece, o tempo todo, comparações com a geração à qual se opõe, ou seja, a adulta. Se os jovens dos anos 1950 eram beatniks, esta é surfista. Uma oposição que acaba por sublinhar o "hedonismo do momento", passageiro, superficial, inconsistente, tanto quanto parece ser seu gosto pela literatura.

The vast majority of the Now Generation has little time for the far-out revels of the beatniks. In consequence, perhaps, its leisure time Happenings have an imaginative opulence that far transcends the entertainments of its parents. The result, as one authority puts it, is "a kind of hedonism of the moment." That hedonism was vibrantly evident last week on the beaches of Florida, where the vacationing young had arrived in force. While the sands thundered to the Big Beat of transistors at full blast, surfers leafed lightly over the waves, and girls in Bermuda-length "cutoffs" or gaudy minishifts strolled languidly down the strand. Mostly, they read: Hans Reichenbach's The Rise of Scientific Philosophy, giant Batman comics, In Cold Blood, J.R.R. Tolkien's Lord of the Rings, and a strategic paperback titled How to Get Ahead in the Army.

A matéria também menciona a estreita relação entre juventude e música, ao afirmar que ela é "o meio básico" dessa geração. Pela folk music, segundo a revista, revela-se, ao encontro de todo o seu "ceticismo e hedonismo", sua "visão lírica única do mundo".

For all their skepticism and hedonism, the Now Generation's folk art reflects a uniquely lyrical view of the world. Music is its basic medium, having evolved from the brassy early days of rock ' $n$ ' roll into the poignant, pithy beat of folk-rock (or "Rock-Bach" as the West Coast enthusiasts call it).

São inúmeras as passagens que, se extraídas dessas páginas da Time Magazine, poderiam nos servir de exemplo sobre como se dá a construção da noção de juventude, naquele momento histórico e sociocultural norte-americano, em oposição a uma situação, hegemônica e adulta, perceptivelmente preocupada com a iminente ameaça à ordem, porém suficientemente controlada - inclusive pela mídia. 


\section{Mídia e juventude}

Mais recentemente, acumulam-se anúncios publicitários em que figura tal simbolismo jovem, direta ou indiretamente, no conceito criativo que vende bens materiais e imateriais. Em outras palavras, a juventude é um conceito publicitário (PEREIRA, 2010), desvinculado daquilo que o inspira, ou seja, um público-alvo de faixa etária correspondente.

O corpus deste trabalho se baseia nas revistas Realidade e Veja, especificamente dos anos de 1967 e 1968 - escolhidos por serem considerados, pelos próprios veículos de comunicação da época, como emblemáticos pela participação dos jovens em diversas sociedades, não somente na brasileira. A pesquisa documental, de maneira mais ampla, vem sendo realizada também em outros veículos impressos, como jornais ( $O$ Globo, Jornal do Brasil, Folha de São Paulo) e revistas (Época, Manchete, Pop, entre outras), em edições que vão de 1960 até 2010, totalizando mais de 4 mil referências, entre anúncios, capas e matérias jornalísticas.

O critério de seleção está baseado na presença de dois aspectos: referência explícita, no texto, ao jovem (ou juventude) e/ou o uso de imagens associadas a bens materiais e valores referentes a esse grupo. Para o recorte específico deste artigo, foram consideradas peças que fizessem, de alguma forma, oposições entre categorias como adulto e jovem, hippie e não-hippie, entre outras, a fim de ressaltar as formas de representação midiática de diferentes tipos ideais presentes no imaginário do contexto analisado.

A revista Realidade teve lugar na mídia brasileira entre os anos de 1966 e 1976. É considerada por muitos como uma referência editorial do gênero, principalmente por sua participação estética e política nos seus três primeiros anos de publicação. Produto da Editora Abril, Realidade foi um marco do jornalismo impresso por ter reunido um grupo de intelectuais e jornalistas que buscavam retratar a realidade de um país em ebulição política.

Em setembro de 1967, na edição especial dedicada aos jovens (Figura 2), Realidade registrou o mito (FARO, s/d) em que se transformava a juventude, apresentando uma espécie de dossiê acerca do "mundo deles", como a própria matéria indica. A revista apresentava, então, os resultados de uma extensa investigação realizada por um instituto de pesquisa e também de um questionário publicado no mês de julho do mesmo ano, respondido por seus leitores. No contrafluxo do jornalismo tradicional, que costumeiramente tratava do tema da adolescência e da juventude associado a questões da família, Realidade procurou ir um pouco além.

O lançamento da primeira edição de Veja, em 1968, foi a saída que a Editora Abril encontrou para sanar prejuízos editoriais que envolviam, inclusive, a Realidade, segundo Faro (ibid.). Respaldada por estudos mercadológicos que anunciavam o declínio da demanda por revistas ilustradas, a Abril investiu em um produto de cunho informativo, acompanhando a mudança no campo da comunicação, capitaneada pelo crescimento e consolidação da televisão no país e no mundo (ibid.). 
Time e Realidade, no mesmo ano, elegeram a juventude como um tema relevante e dedicaram a ela, portanto, edições que se tornaram históricas. Trata-se do prenúncio de um processo de reificação de algo que, até ali, estava relegado, no máximo, à categoria de subcultura - ou de cultura jovem, um conjunto de bens materiais que se firmam como bens simbólicos, sobretudo, por sustentação dos meios de comunicação de massa.

A juventude como estilo de vida ou, no limite, ideologia, ao contrário do que possa parecer em estudos recentes dedicados ao tema, não é produto da contemporaneidade tardia, como indicarão alguns dos anúncios dos anos 1960 aqui analisados. Embora nossa sociedade explicite o "ser jovem" como um valor que orienta as práticas de consumo em suas mais diversas expressões - desde o vestuário até o corpo que ele encobre -, seria ingênuo afirmar que se trata de algo exclusivo de um dado contexto histórico ou sociológico.

Tal como um fenômeno social, elabora-se em processo. O que se revela nos anúncios analisados é a existência, no período pesquisado, de um discurso persuasivo que começa a se apropriar desse conjunto de bens materiais e imateriais que delineia este "ser jovem" e que empresta, aos produtos e marcas anunciados, o que há neles de simbólico. É a juventude como um valor que se anuncia, em todos os sentidos.

As duas revistas escolhidas para a coleta do corpus desta pesquisa, embora publicadas pela mesma editora, possuíam linhas editoriais bastante distintas. Enquanto a revista Veja tinha, como já foi dito, um cunho mais "informativo", a revista Realidade aproximava-se do estilo ilustrado: as edições apresentavam verdadeiros ensaios fotográficos. Mais que isso, a Realidade destacava-se da outra revista por apresentar matérias bastante provocadoras, da política à sexualidade. Em suas edições, encontravam-se, mensalmente, matérias sobre prostituição, streapers, dançarinas de aluguel, entre outras, com caprichado material fotográfico.

Para o olhar que aqui nos interessa, porém, vale ressaltar que os anúncios encontrados na revista Realidade não pareciam acompanhar a mesma linha polêmica do jornalismo. O que se encontra, em suas páginas, são anúncios que tratam a juventude da mesma forma que a revista Veja, considerando os tipos ideais mais comuns, desde o comportado até o hippie - sem afirmar, é importante frisar, que apenas o lado positivo deles tenha sido considerado nas mensagens publicitárias, como será possível verificar, em alguns dos exemplos explorados mais adiante.

Comparativamente Veja e Realidade destinavam seu espaço publicitário para anúncios que, não obrigatoriamente, acompanhavam a proposta editorial, jornalística, presente nos dois veículos; ao contrário, muitas das peças aqui analisadas poderiam estar, ou de fato estiveram impressas nas duas revistas ao mesmo tempo.

\section{Representações das juventudes}

A seguir, serão analisados dez anúncios publicitários das duas revistas, Veja e Realidade, publicados durante os anos 1967 e 1968. Para efeito de análise, serão usadas 
algumas categorias, estabelecendo uma classificação pelo tipo ideal representado na mensagem publicitária. Esse sistema de classificação se sustenta nas representações do "estilo de vida", aqui considerado como o conjunto de "práticas que um indivíduo abraça, não só porque essas práticas preenchem necessidades utilitárias, mas porque dão forma material a uma narrativa particular da autoidentidade" (GIDDENS, 2002, p. 79).

Evidentemente, baseado nesse conceito de Giddens, a ideia é considerar o conjunto simbólico presente em cada narrativa publicitária - práticas, necessidades, forma material e (auto)identidade - e associar a um tipo ideal. Trata-se, sobretudo, de uma forma de evidenciar a pluralidade do que seria o "ser jovem" presente na publicidade, ainda que sua narrativa tenda a homogeneizar o que, no jargão do campo, é chamado de público-alvo ou, ainda, aspiracional, pois, nem sempre, o anúncio com jovens é enunciado para jovens.

\section{Esticadinhos}

No anúncio da marca de tecidos Tergal (REALIDADE, 1967b) (Figura 3), apresentam-se dois tipos de jovens: os "cabeludinhos" e os "esticadinhos". De um lado, os que fazem arte e, do outro, os que a compram.

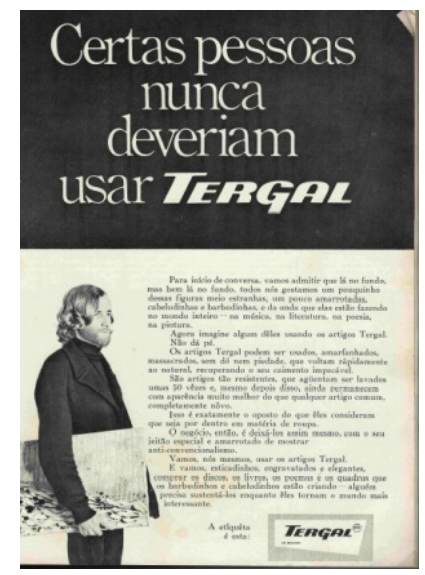

Fig. 2. Barbudinhos $x$ Esticadinhos

O texto dessa peça publicitária descreve um mundo dividido entre nós e eles. Nesse caso, o desejo da marca Tergal é de não ter como consumidores os jovens "da onda", mas de mantê-los por perto, ainda que seja para marcar o contraste que a então inovadora tecnologia desse tecido que não amarrota promete.

Para início de conversa, vamos admitir que lá no fundo, mas bem lá no fundo, todos nós gostamos um pouquinho dessas figuras meio estranhas, um pouco 
amarrotadas, cabeludinhas e barbudinhas, e da onda que elas estão fazendo no mundo inteiro - na música, na literatura, na poesia, na pintura. Agora imagine algum deles usando os artigos Tergal. Não dá pé. [...] Isso é exatamente o oposto do que eles consideram que seja por dentro em matéria de roupa. O negócio, então, é deixá-los assim mesmo, com o seu jeito de demonstrar anticonvencionalismo. Vamos, nós mesmos, usar os artigos Tergal. (Ibid.)

E vamos, esticadinhos, engravatados e elegantes, comprar os discos, os livros, os poemas e os quadros que os barbudinhos e cabeludinhos estão criando - alguém precisa sustentá-los enquanto eles tornam o mundo mais interessante. (Ibid.)

O texto revela que há um encantamento com esse modelo de juventude "amarrotada" que torna "o mundo mais interessante". Afinal, são esses jovens que estão criando a música, a literatura, a poesia e a pintura, demonstrando um "anticonvencionalismo" que, por outro lado, não interessa ser associado à marca. Evidentemente, o anúncio da Tergal refere-se aos hippies, cujo estilo de vida pautava, no mundo inteiro, a moda, as artes e as matérias jornalísticas das principais revistas. Por certo, esse não era o estilo de vida desejado como um modelo a ser imitado na publicidade nesse momento, mas, de certa forma, também compunha o imaginário social daquele final dos anos 1960.

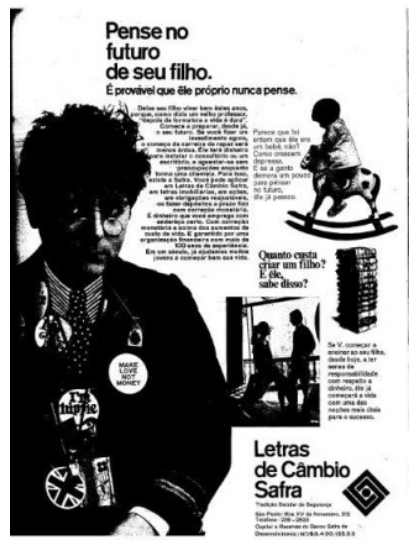

Fig. 3. O jovem sem futuro

Outro anúncio que ilustra bem a representação do jovem que trabalha e sustenta a criatividade artística daquele outro, sem futuro, ou seja, o hippie, é o assinado pelas Letras de Câmbio Safra (REALIDADE, 1968b). Na imagem em preto e branco, um rapaz com 20 poucos anos veste terno e gravata, mas parece triste e derrotado (Figura 4). Em seu paletó, diferentes bottons - "make love not money" e "ím hippie", além de ícones ideológicos, como cruz, flores e símbolo da paz - indicam que tal estilo de vida não "garante o futuro" de ninguém, nos moldes do modelo capitalista. Entendendo-se 
por "futuro", como o próprio texto afirma, "instalar o consultório ou um escritório, e aguentar-se sem preocupação enquanto forma uma clientela".

Esse jovem frustrado é o resultado, portanto, de uma vida que não foi planejada antecipadamente, ou, pior, de pais que nunca pensaram nele, já que "é provável que êle próprio nunca pense", como defende o subtítulo da mensagem. Em outras palavras, ideologia não sustenta o futuro; dinheiro, sim.

Considerando esses dois anúncios publicados em Realidade, identificamos uma clara referência aos movimentos culturais transgressores, contraculturais, antiburocratas, como indesejáveis, já que em nada contribuem para a imagem da marca. Os esticadinhos, com o futuro garantido financeiramente, sustentarão o mundo, no futuro; os barbudinhos, ao contrário, lembram o "hedonismo de momento" a que se refere a Time Magazine, cujo texto foi analisado em outro momento, neste texto.

\section{Hedonistas}

O hedonismo, porém, nem sempre era indesejado como valor. Ao contrário, ele adere, com frequência, à noção de juventude, e, naquele contexto, já se fixava como um conceito para algumas marcas. Como faz, por exemplo, o surfista de terno do anúncio da mesma marca Tergal (VEJA, 1968) (Figura 4). O terno, mais uma vez, aparece como parte do universo jovem - melhor ainda, em tecido que "não desbota, não amarrota, é leve, tem ótimo caimento", e que "não perde o vinco, mesmo depois de molhado". O surfista, como se vê, não abre mão nem da elegância - aqui, associada ao mundo do trabalho (adulto) -, e nem do prazer, já que está em ação, surfando na onda. Conservador, mas bem-sucedido. Responsável, mas bon vivant.

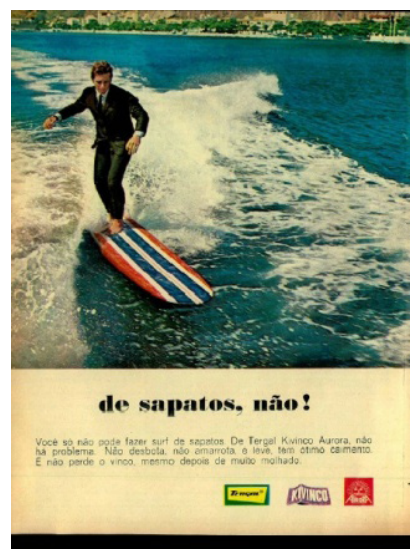

Fig. 4. Surf "esticadinho" 
O ufanismo, marca do regime ditatorial do presidente Emílio Garrastazu Médici, eleito em 1969, já se anunciava num modelo de juventude, aquele que aposta no sucesso profissional, no progresso e no futuro. Porém, o prazer, desde então, já era um símbolo de jovialidade, o que contribui para a construção da imagem positiva dessas marcas. Ao mesmo tempo, esse prazer representado nos anúncios é diretamente associado a sucesso, dinheiro e êxito profissional, como comprova a famosa campanha dos cigarros Hollywood, que já pode ser encontrada na contracapa da edição de maio de 1969 (VEJA, 1969) (Figura 5).

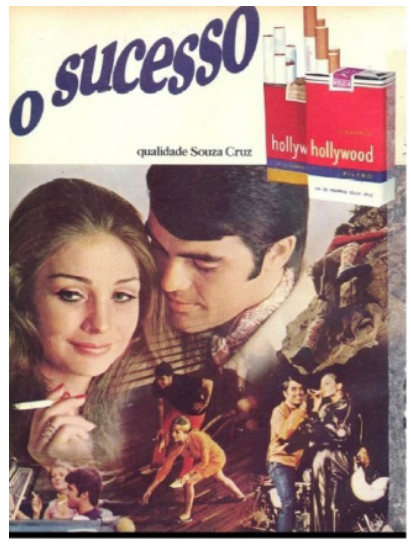

Fig. 5. Sucesso, prazer e juventude

\section{Jovem adulto}

Se a jovialidade é um valor positivo como conceito de campanha, há ainda um tipo de publicidade que atribui a maturidade a um jovem que, em muito, assemelha-se àquele presente nos dois exemplos anteriores.

A Revista Seleções publicou, em página inteira (Figura 6) (REALIDADE, 1968b), um dado que explicita o seu interesse em atingir um determinado perfil de leitor: " $58 \%$ dos leitores de Seleções têm menos de 30 anos". A imagem é de uma mulher, aparentemente com menos de 30 anos, moderna para os padrões de moda da época, de óculos, que parece olhar firmemente para o leitor. Ela representa, pelo que indica o texto, alguém bem-sucedido, consumidor exigente e inteligente: "Vou de Shell, uso Topeka, dirijo Karmann Ghia, fui a Nova York pela Varig e a Londres pela Pan American, fiz todas as provas (e passei) com Parker. Leio Seleções". 


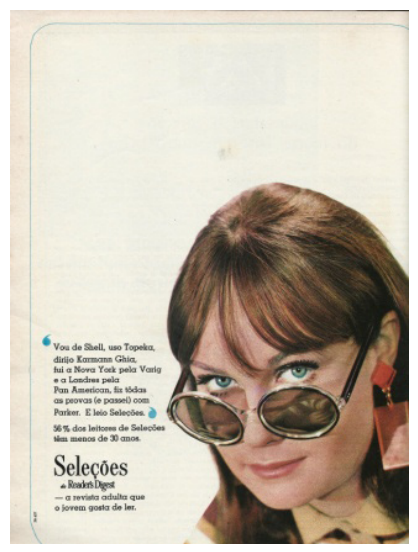

Fig. 6. Bem-sucedida, consumidora e inteligente.

O sucesso, portanto, passa a transitar, também, no universo do jovem, pelo menos pela publicidade. E sucesso refere-se a poder de consumo, reconhecimento profissional, mérito pelas conquistas - coisas que pertenciam ao mundo dos adultos, a uma esfera profissional, mas que cabe muito bem no tipo de juventude desejável, naquele contexto de 1968, em que ela própria contestava a ordem vigente.

Anunciando a si mesma, a agência Propaga Publicidade afirma que "Ser adulto aos nove anos é sonho de muita gente..." (ibid.) (Figura 7), e ilustra esse título com uma fotografia em preto e branco de uma criança "fazendo a barba" - prática comum entre os meninos, quando querem imitar seus pais e brincar de adulto.

No texto, lê-se: "Juventude, dinamismo, vida e fôrça de vontade são o segredo de nosso sucesso. É com criatividade, capricho, conhecimento do mercado e elevada técnica publicitária que conquistamos a confiança de nossos clientes". Mais uma vez, a noção de juventude surge como um caminho para o sucesso - mas também a de "dinamismo", "vida" e "força", que, associados, compõem a imagem do que é o "ser jovem". "Criatividade e capricho" são valores ligados à imagem e que remetem, portanto, a algo mais lúdico (ingenuidade pueril), porém, só se sustentam se estiverem acompanhados de "conhecimento do mercado e elevada técnica", que só podem ser conquistados com racionalidade, sabedoria, experiência e senioridade (maturidade). Do mesmo modo que, para a marca anunciada, é importante ser percebida por sua competência profissional, o conceito de jovialidade indica modernidade, atualidade e inovação. 


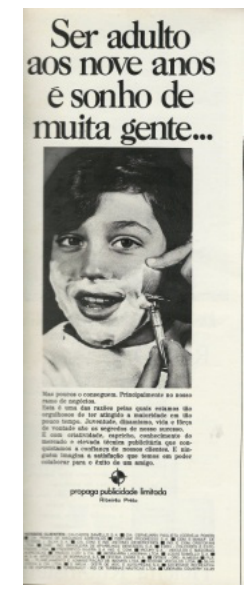

Fig. 7. Uma agência jovem

\section{Fortes}

De forma bastante semelhante, outros anúncios recorrem à noção de juventude acionando o vigor e a força do corpo jovem. A descrição do automóvel da marca Galaxie (REALIDADE, 1967a) (Figura 8) demonstra bem isso: "Automóvel de físico jovem. Automóvel de espírito jovem. Ford Galaxie. Teste os músculos e os nervos do Ford Galaxie".

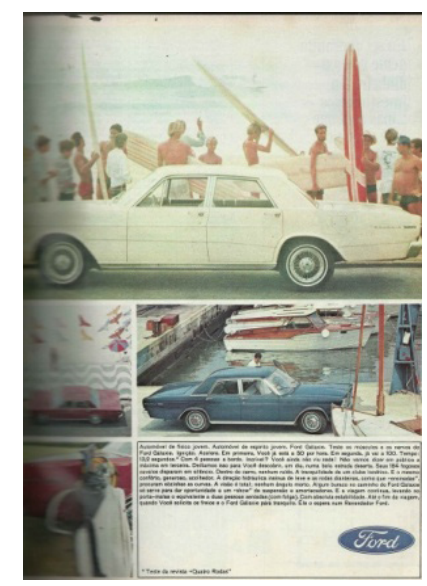

Fig. 8. Carro de "músculos jovens"

O produto anunciado, um automóvel, ganha um espírito jovem - o que denota um valor simbólico etéreo, mas sustentado culturalmente por uma gama de características reforçadas pelas imagens; ao mesmo tempo, recorre ao corpo jovem, algo material 
e evidenciado, também, na fotografia maior: o Ford Galaxie tem "músculos", ou seja, é forte e tem vitalidade, assim como os surfistas que servem de pano de fundo para um dos recortes do anúncio. Em outras palavras, "ser jovem" é um estilo de vida que pressupõe disposição e um corpo saudável, musculoso.

A recorrente presença dos esportes e da diversão em algumas das peças até aqui analisadas, incluindo essa do Galaxie, vão ao encontro da construção do imaginário do jovem desejável socialmente, qual seja, aquele que pode ser disciplinado e, portanto, controlado. A força corporal é mencionada no anúncio, mas, nas imagens, não há nenhuma explicitação a esse respeito - nenhum "músculo", nenhuma indicação de força, apenas surf, vela e mar; natureza e prazer hedonista.

\section{Influenciadores}

Tal vitalidade também pode ser observada na publicidade da marca Renaux (VEJA, 1968) (Figura 9). O jovem é, pelo texto, "incansável", "bonito" e "vibrante". Ele dita a moda, pois "sabe se vestir melhor". Mais ainda, é representado como um influenciador, uma autoridade quando o assunto é moda.

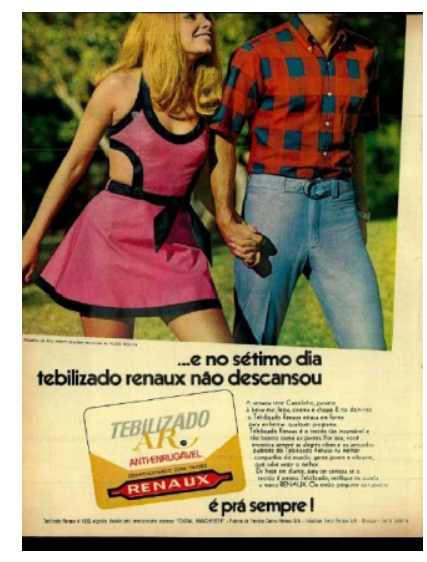

Fig. 9. Jovens incansáveis

Também no campo da cultura, os jovens tornam-se referência: no primeiro anúncio da Tergal, citado anteriormente, são eles que produzem a arte "na música, na literatura, na poesia, na pintura". Na página da Veja de 1968 (VEJA, 1968b), a marca Nescafé (Figura 11) ratifica essa construção social da juventude, associando-a a valores como "novidade", "praticidade", "modernidade". Um produto "para gente moça ou com espírito moço", da "cor de Ipanema, com muita bossa nova": 


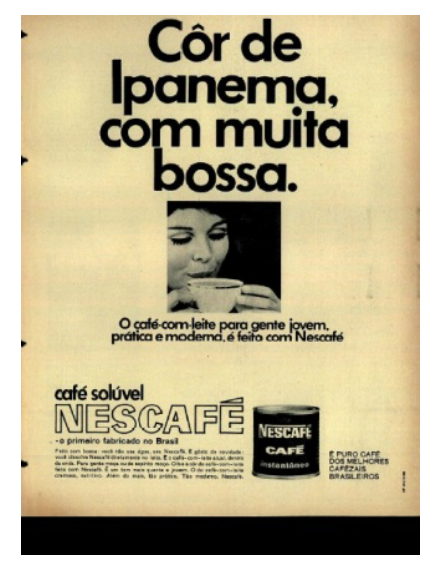

Fig. 10. Modernidade e Bossa-nova

Na Figura 11, a marca de cigarros Capri deixa-se representar por dois jovens, um casal: ela, em primeiro plano, vestindo uma minissaia com estampa psicodélica "I love Capri" (REALIDADE, 1968a); ele, mais atrás, com olhar provocante em sua direção, segura uma guitarra. Música e moda, portanto, compõem práticas e gostos, ambos relacionados à ideia de modernidade através do título "O cigarro moderno".

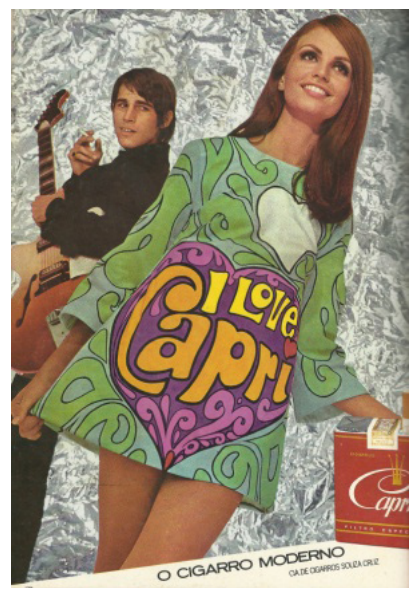

Fig. 11. Moda e cigarro

Se, entre meados de 1950 e início de 1960, a cultura juvenil se consolida sustentada pela cultura de massa e, consequentemente, pelo consumo de bens culturais importados, sem, ainda, anunciar-se por sua ação social - o que não significa passividade ou ausência de transgressão -, nesse contexto analisado, através da publicidade, o que se encontra é o jovem com atitude, influenciador na moda e na cultura. 
Tal processo toma forma com o movimento da Contracultura, do início da década, e afirma-se, principalmente, através das revoltas políticas de 1968, refletindo, portanto, na intenção das marcas anunciantes em tomar de empréstimo categorias como "incansável", "vibrante", "novidade", "modernidade", contribuindo para fixar, na noção de juventude, esse conjunto simbólico que acaba por transformá-la, enfim, em um conceito publicitário (PEREIRA, 2010).

\title{
Considerações finais
}

As representações do "ser jovem" nos anos pesquisados anunciam as que povoam nosso contexto, mais de cinquenta anos depois. A ruptura entre os dois mundos o jovem e o adulto - encontra lugar nas ruas do mundo inteiro, como reportam as revistas e a publicidade analisadas. São mundos diferentes servindo ao mesmo propósito do consumo e da indústria midiática. Porém, as diversas páginas ímpares aqui analisadas firmam o papel do jovem como um influenciador, um modelo a ser imitado, aquele que perdura, há décadas, inspirando um estilo de vida à moda Tergal - sem vincos, sem desbotar, nem amarrotar.

\author{
Cláudia da Silva Pereira é pesquisadora e professora do \\ Programa de Pós-Graduação em Comunicação da Pontifícia \\ Universidade Católica do Rio de Janeiro (PUC-RIO); \\ é doutora em Antropologia pelo PPGSA-IFCS. \\ caupereira@gmail.com
}

\section{Referências}

CALDAS, W. A cultura juventude de 1950 a 1970. São Paulo: Musa Editora, 2008.

DEBERT, G. G. A cultura adulta e juventude como valor. Revista Kairós, São Paulo, v. 7, n. 2, 2004.

FARO, J. S. Revista Realidade, 1966 - 1968: tempo da reportagem na imprensa brasileira, s/d. Disponível em: <http://www.ufrgs.br/ensinodareportagem/artigos/revistarealidade.pdf $>$. Acesso em: 25 ago. 2012.

GIDDENS, A. Modernidade e identidade. Rio de Janeiro: Jorge Zahar, 2002.

GOFFMAN, K.; JOY, D. Contracultura através dos tempos: do mito de Prometeu à cultura digital. Rio de Janeiro: Ediouro, 2007.

GROSSBERG, Lawrence. The politics of youth culture: some observation on rock and roll in american culture. Disponível em http://www.jstor.org/stable/466325, 1983..

Some preliminary conjunctural thoughts on countercultures. Springerin, Viena (Áustria), n. 3, 2010. Disponível em: <http://www.springerin.at/dyn/heft_text.php?textid=2366\&lang=en> Acesso em: 10 mar. 2013. 
HOBSBAWN, E. Revolução Cultural. In: Era dos Extremos: o breve século XX: 1914-1921. São Paulo: Companhia das Letras, 1995.

MORIN, E. Cultura de massas do século XX: o espírito do tempo I: neurose. Rio de Janeiro: Editora Forense Universitária, 2011.

Cultura de massas do século XX: o espírito do tempo II: necrose. Rio de Janeiro: Editora Forense Universitária, 2009.

ORTIZ, R. Mundialização e Cultura. São Paulo: Brasiliense, 2000.

PEREIRA, C. Juventude como conceito estratégico para a Publicidade. Revista Comunicação, Mídia e Consumo. São Paulo, ESPM, v. 7, n. 7, p. 37-54, mar-2010.

REALIDADE. São Paulo: Editora Abril, 13, abr. 1967a

_. São Paulo: Editora Abril, 17, ago. 1967b.

_. São Paulo: Editora Abril, 29, ago. 1968a.

. São Paulo: Editora Abril, 68, ago. 1968b.

TIME MAGAZINE. Disponível em http://www.time.com/time/printout/0,8816,843150,00.html. Edição de 6 de janeiro de 1967.

VEJA. São Paulo: Editora Abril, 2, 18 set. 1968a.

. São Paulo: Editora Abril, 9 set. 1968b.

São Paulo: Editora Abril, 21 maio 1969.

Artigo recebido em abril de 2013

e aprovado em maio de 2014. 